Rev. Biol. Neotrop. 4(2): 83-100. 2007

\title{
ITOSSOCIOLOGIA DA COMUNIDADE LENHOSA DE UMA ÁREA DE CERRA- do rupestre no Parque Estadual dos Pireneus, Pirenópolis, GoIÁs
}

\section{Iona'i OsSami de Moura}

Programa de Pós-Graduação em Ecologia, Instituto de Ciências Biológicas, Universidade de Brasília, Brasília, Distrito Federal, Brasil; e-mail: ionamoura@gmail.com

\author{
Vera Lúcia Gomes-KLein \\ Departamento de Biologia Geral, Instituto de Ciências Biológicas, Universidade Federal de \\ Goiás, Campus II, Goiânia, Goiás, Brasil; e-mail: vlgomes.ufg@gmail.com
}

Jeanine Maria Felfili

Faculdade de Tecnologia, Departamento de Engenharia Florestal, Universidade de Brasília, Brasília, Distrito Federal, Brasil; e-mail: felfili@unb.br

\section{Heleno Dias Ferreira}

Departamento de Biologia Geral, Instituto de Ciências Biológicas, Universidade Federal de Goiás, Campus II, Goiânia, Goiás, Brasil; e-mail: heleno@icb.ufg.br

\begin{abstract}
Resumo: Este trabalho teve como objetivo estudar a composição florística e a estrutura fitossociológica de uma área de cerrado sensu stricto sobre afloramentos rochosos no Parque Estadual dos Pireneus, município de Pirenópolis, Goiás. A área de estudo localiza-se entre as coordenadas 15047'71"S - 48 $49^{\prime} 96^{\prime \prime} \mathrm{W}$ e $15^{\circ} 47^{\prime} 77^{\prime \prime} \mathrm{S}-48^{\circ} 50^{\prime} 15^{\prime \prime} \mathrm{W}$, a $1.355 \mathrm{~m}$ de altitude. Foram sorteadas dez parcelas de 20 $\mathrm{m} \times 50 \mathrm{~m}$ para proceder à amostragem de todos os indivíduos lenhosos com $\mathrm{DB}_{(30 \mathrm{~cm})} \geq 5 \mathrm{~cm}$. Foram encontradas 30 famílias botânicas, contendo 45 gêneros e 56 espécies. A família Myrtaceae apresentou a maior riqueza de espécies (8), seguida por Fabaceae e Melastomataceae (6 cada), Malpighiaceae (4) e Clusiaceae (3). A densidade observada foi de 507 indivíduos/ha, a área basal, de 3,91 $\mathrm{m}^{2} / \mathrm{ha}$ e as árvores mortas em pé representaram 9,07\% do número total de indivíduos. O índice de Shannon $\left(\mathrm{H}^{\prime}\right)$ foi de 3,33 nats/ind. Os índices de similaridade de Czekanowski entre parcelas indicaram que a diversidade beta foi alta, principalmente pela diferenciação na densidade de indivíduos entre parcelas. A área apresenta composição florística característica da região, com espécies adaptadas à pequena profundidade do solo e ao substrato rochoso, e espécies generalistas das fisionomias de Cerrado.
\end{abstract}

Palavras-chave: Brasil, Cerrado, diversidade, estrutura comunitária, Goiás, Serra dos Pireneus.

ABSTRACT: This work aimed to study the floristic composition and phytosociology of an area of cerrado sensu stricto located on rocky outcrops in Parque Estadual dos Pireneus, municipality of Pirenópolis,

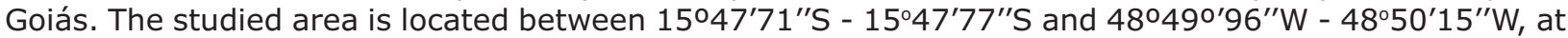
the altitude of $1.355 \mathrm{~m}$. Ten $20 \mathrm{~m} \times 50 \mathrm{~m}$ plots were randomly sampled to include all woody individuals with $\mathrm{BD}_{(30 \mathrm{~cm})} \geq 5 \mathrm{~cm}$. We registered 30 botanical families encompassing 45 genera and 56 species. Myrtaceae family showed the highest number of species (8), followed by Fabaceae and Melastomataceae (6 each), Malpighiaceae (4) and Clusiaceae (3). There were 507 individuals/ha, the basal area was 3.91 $\mathrm{m}^{2} /$ ha , and the standing dead trees represented $9.07 \%$ of the total number of individuals. Shannon's $\left(\mathrm{H}^{\prime}\right)$ index was 3.33 nats/ind. Czekanowski similarity indices suggest that the beta diversity was high, mostly due to variation in species density between plots. The area has a characteristic flora of this region and species composition restricted to rocky outcrops adapted to shallow soils near the rocky substrate as well as generalist species of Cerrado physiognomies.

Key-words: Brazil, Cerrado, diversity, community structure, Goiás, Serra dos Pireneus. 


\section{INTRODUÇÃO}

Bioma Cerrado representa 22\% da superfície do Brasil (Oliveira-Filho \& Ratter, 2002) e apresenta grande heterogeneidade florística e fisionômica. Sua distribuição é determinada, principalmente, por gradientes edáficos, mas também por relevo, geologia, níveis de flutuação do lençol freático e clima (Miranda et al., 2003), além de históricos de fogo na área (Furley, 1999). O Cerrado possui a flora mais rica entre as savanas do mundo (Alho \& Martins, 1995), com mais de 6.000 espécies vasculares (Mendonça et al., 1998), sendo $44 \%$ endêmicas (Klink \& Machado, 2005), e está classificado como um dos hotspots mundiais de biodiversidade, ou seja, locais onde concentrações excepcionais de espécies endêmicas estão sofrendo significativas perdas de habitat (Myers et al., 2000).

Existe uma variação no gradiente de biomassa característica da paisagem do Cerrado, desde o campo limpo de cerrado até o cerradão, passando pelo campo sujo de cerrado, campo cerrado e cerrado sensu stricto (Almeida Júnior, 1993). Um dos principais tipos fitofisionômicos desse bioma é o cerrado sensu stricto, que apresenta os estratos arbóreo e arbustivo-herbáceo bem definidos (Ribeiro \& Walter, 1998), com cobertura arbórea variando de $10 \%$ a $60 \%$ (Eiten, 1972) em um mesmo local. Segundo Ribeiro \& Walter (1998), esta fitofisionomia pode ser subdividida em quatro subtipos com base na densidade ou no ambiente em que se encontram: cerrado denso, cerrado típico, cerrado ralo e cerrado rupestre. Esses autores ainda afirmam que o cerrado rupestre ocorre em solos rasos com presença de afloramentos de rocha e apresenta elementos florísticos adaptados ao ambiente rupícola, possuindo cobertura arbórea variável de 5\% a $20 \%$, altura média de $2 \mathrm{~m}$ a $4 \mathrm{~m}$ e estrato arbustivo-herbáceo também destacado. Estudando a estrutura de cerrado sobre rochas, Moura (2006) e Felfili \& Fagg (2007) encontraram fisionomias com densidades de árvores que equivalem ao cerrado sensu stricto, mostrando que o cerrado sobre rochas apresenta ampla variação estrutural. Reatto et al. (1998) estimam que o solo litólico ocorra em 7,3\% do bioma Cerrado, que tem como vegetação natural predominante o campo rupestre e o cerrado rupestre.

O cerrado sobre afloramentos rochosos ocorre no estado de Goiás, principalmente nas áreas altas de várias serras, como nas Serras dos Pireneus, Dourada e de Caldas Novas (Rizzo, 1996). Eiten (1993) discorreu sobre a existência de pequenas áreas com vegetação de cerrado, nas quais há solos típicos de campos rupestres (raso, de areia pura ou derivada de quartzito, com alto teor de húmus), e também sobre afloramentos de quartzito, localizadas em Goiás, perto de Cristalina, e também nas Serras de Caldas Novas, Dourada e dos Pireneus. Em alguns locais, esta fisionomia apresenta cobertura arbórea mais densa que a descrita por Ribeiro \& Walter (1998).

Várias áreas de cerrado sensu stricto vêm sendo analisadas no âmbito do Projeto Biogeografia do Bioma Cerrado (Felfili et al., 2004) e de outros estudos, mas ainda são escassas as amostragens em cerrado sobre afloramentos rochosos (Amaral et al., 2006, Felfili \& Fagg, 2007).

Assim, neste estudo objetivou-se realizar a análise da composição florística e da estrutura comunitária do componente lenhoso de uma área de cerrado sensu stricto sobre afloramentos de rocha próxima aos Três Picos, no Parque Estadual dos Pireneus, no município de Pirenópolis.

\section{MATERIAL e mÉtodos}

ÁREA DE ESTUdo

Neste trabalho, foi amostrado um trecho de cerrado sensu stricto sobre afloramentos rochosos próximo aos Três Picos, no Parque Estadual dos Pireneus, município de Pirenópolis, Goiás (Figuras 1 e 2). O parque dista 124 km de Goiânia e ocupa uma área de 2.822 ha no alto da Serra dos Pireneus. Está situado entre os paralelos $15^{\circ} 45^{\prime} \mathrm{S}-15^{\circ} 50^{\prime} \mathrm{S}$ e os meridianos $48^{\circ} 45^{\prime} \mathrm{W}-48^{\circ} 55^{\prime} \mathrm{W}$, às margens da rodovia BR-070 e seus limites abrangem os municípios de Cocalzinho, Corumbá de Goiás e Pirenópolis (Figura 1). A altitude do parque varia de $1.100 \mathrm{~m}$ a $1.385 \mathrm{~m}$, tendo como ponto culminante o Pico dos Pireneus. 
PARQUE ESTADUAL DOS PIRENEUS

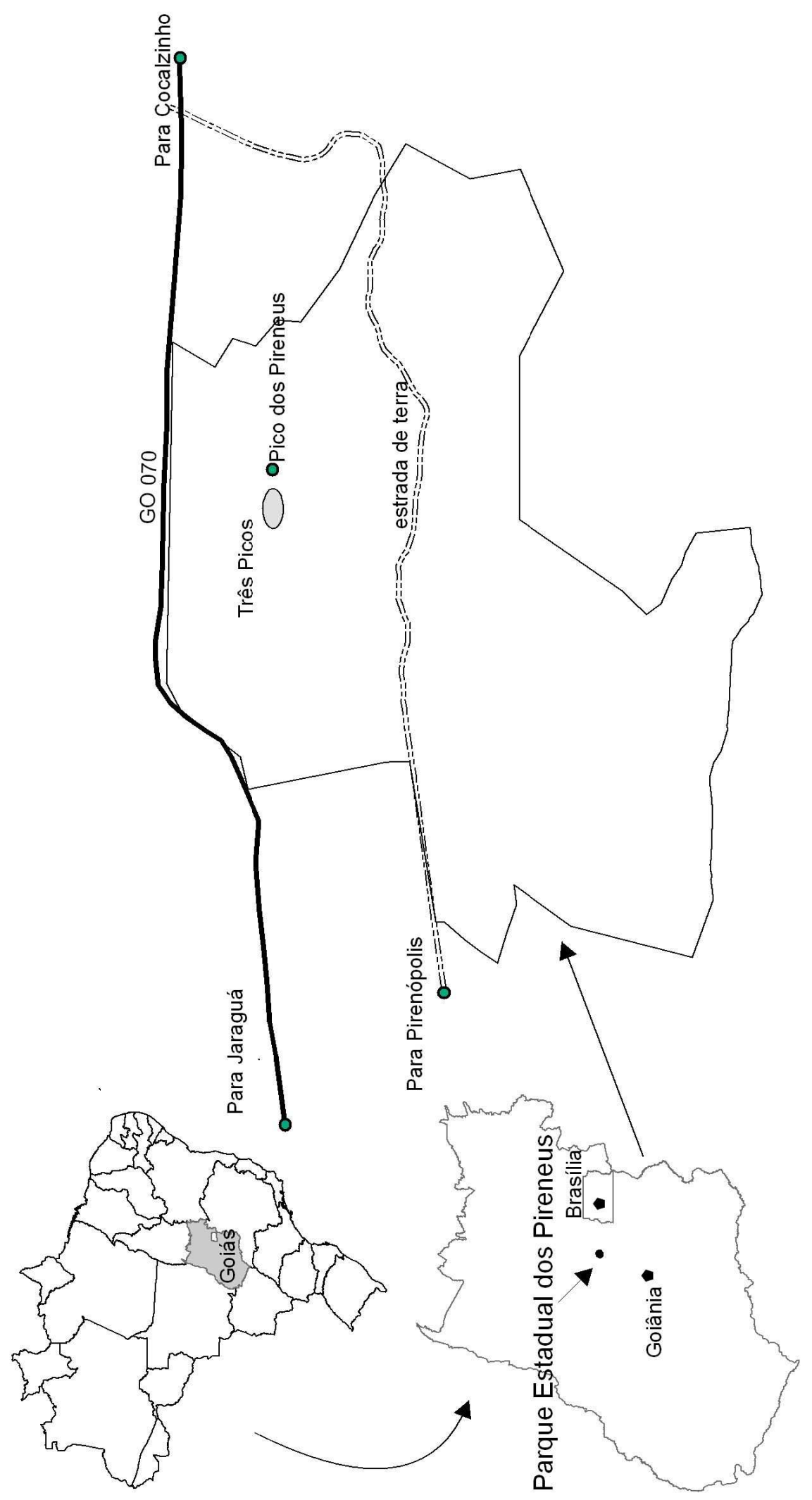

Figura 1 - Localização da área de estudo, em trecho de cerrado rupestre próximo aos Três Picos, no Parque Estadual dos Pireneus, Pirenópolis, Goiás. 


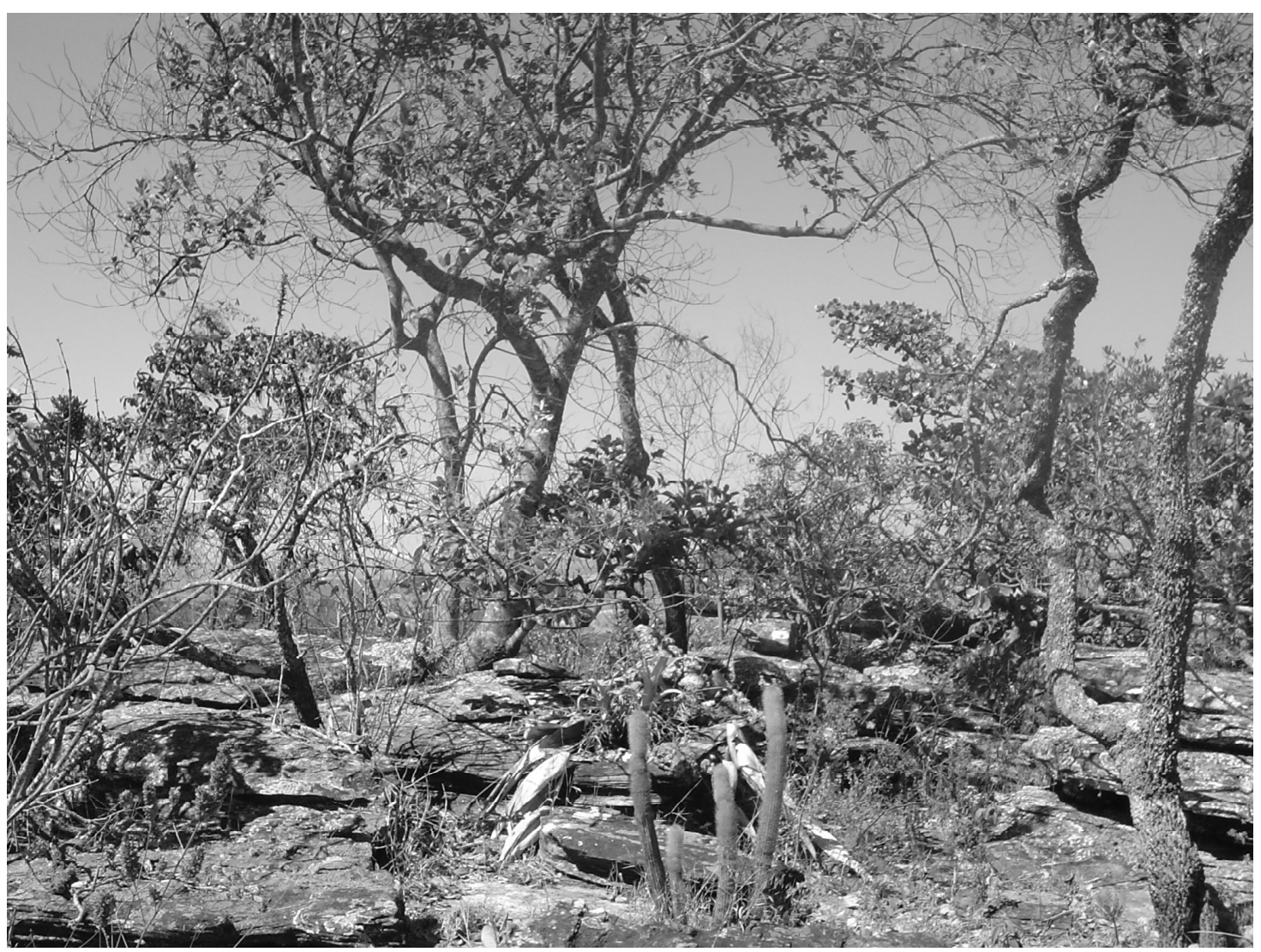

Figura 2 - Detalhe da área de estudo em cerrado rupestre próxima aos Três Picos, no Parque Estadual dos Pireneus, Pirenópolis, Goiás (Foto de I. O. Moura).

Utilizou-se GPS Garmin Etrex, sempre no vértice localizado mais ao sul das parcelas, para as medições das coordenadas geográficas de todas as parcelas estudadas, localizadas entre as coordenadas $15^{\circ} 47^{\prime} 71^{\prime \prime}$ a $15^{\circ} 47^{\prime} 77^{\prime \prime} \mathrm{S}$ e $48^{\circ} 49^{\prime} 96^{\prime \prime}$ a $48^{\circ} 50^{\prime} 15^{\prime \prime} \mathrm{W}$, e de suas altitudes, que variaram de 1.325 a $1.355 \mathrm{~m}$.

O clima da região é do tipo Aw de Köppen, tropical úmido, caracterizado por duas estações bem definidas: uma seca, que corresponde ao período de outono/inverno, entre os meses de abril e outubro, e outra úmi$\mathrm{da}$, com chuvas torrenciais, correspondendo ao período de primavera/verão (Agência Ambiental de Goiás \& Nativa, 2003b).

O solo predominante no parque é do tipo Cambissolo, pobre em matéria orgânica, pouco profundo e cascalhento, e em grande parte pode ser considerado como Litólico, com ocorrência de lajedos, blocos de rocha de tamanhos variados e afloramentos rochosos em toda a sua extensão (Agência Ambiental de Goiás \& Nativa, 2002). As áreas estudadas encontram-se sobre afloramentos rochosos, nos quais ocorrem rochas do Grupo Araxá (quartzito e uma associação quartzo-muscovita-xisto). A maior parte da área das parcelas amostradas possui mais de $75 \%$ de cobertura de rochas, com ocorrência de solo entre as rochas ou sob a forma de uma delgada camada sobre elas (medida pelos autores).

A área estudada pertence a um parque estadual e, aparentemente, a vegetação mantém suas características originais de cerrado, embora seja percorrida por visitantes e escaladores, além de se situar ao lado do local onde ocorre uma festa tradicional da região, a "Festa do Morro". Essa festividade popular ocorre uma vez por ano, no mês de julho, com a participação de centenas de pessoas, parte das quais acampa no local na ocasião. Esporadicamente, também são encontrados eqüinos e bovinos no local. 
O trabalho de campo foi executado durante o segundo semestre de 2004 e o primeiro de 2005. A amostragem da vegetação do cerrado sensu stricto foi realizada de forma aleatória, conforme metodologia adotada no Projeto Biogeografia do Bioma Cerrado para esta fisionomia (Felfili et al., 1997; Felfili \& Silva Júnior, 2001).

De acordo com Péllico Netto \& Brena (1997), na amostragem aleatória, nenhuma restrição é imposta ao processo de seleção das unidades, sendo obtida uma listagem de todas as unidades potenciais da comunidade e as unidades da amostragem definidas por meio de sorteio. Seguindo esta metodologia, percorreu-se a área em estudo para a confecção de um croqui representando o número de parcelas comportado pela área total, procedendose, então, ao sorteio das parcelas estudadas. Portanto, alocou-se um total de dez parcelas de $20 \mathrm{~m} \times 50 \mathrm{~m}$ aleatoriamente em uma área de $150 \mathrm{~m} \times 350 \mathrm{~m}$ de cerrado sensu stricto sobre afloramentos rochosos.

Em cada parcela foram medidos o diâmetro e a altura de todos os indivíduos lenhosos encontrados com diâmetro igual ou superior a $5 \mathrm{~cm}$, tomado a $30 \mathrm{~cm}$ da superfície do solo. A medição dos diâmetros foi feita com suta metálica sobre a casca. Para a altura, foi considerada a projeção vertical da porção mais alta da copa ao solo, com vara graduada, conforme estipulado por Felfili et al. (2004). Em decorrência de algumas situações particulares da área estudada, foi necessário adaptar os pontos de medição para alguns indivíduos localizados entre rochas, de modo a se obter o diâmetro e a altura, sempre objetivando obter a projeção vertical da copa ao solo para a mensuração da altura (Figura 3).

A identificação taxonômica foi realizada no campo, ou por intermédio da coleta de material para posterior comparação em herbários, ou pelo envio de duplicatas a especialistas. Todos os materiais coletados foram herborizados, etiquetados e identificados por meio de comparação em herbários (UFG e UB) ou de consultas a especialistas e encontram-se depositados no herbário UFG. As famílias de plantas foram apresentadas segundo o sistema do The Angiosperm Phylogeny Group (2003).
A suficiência da amostragem foi avaliada com o uso do cálculo do erro padrão da média em porcentagem (EP\%) e do intervalo de confiança (IC) a $95 \%$ de probabilidade da média da densidade e da área basal das parcelas. Elaborou-se uma curva espécie $x$ área a fim de verificar a abrangência florística da amostragem (Kent \& Coker, 1992; McCune \& Grace, 2002). Avaliou-se a riqueza florística mediante a contabilização dos números de espécies, gêneros e famílias registrados nas parcelas e da comparação com os resultados obtidos em outros levantamentos.

A fitossociologia da comunidade foi analisada por meio dos cálculos de densidade, freqüência e dominância dos indivíduos amostrados, bem como do Valor de Importância (VI), mediante a aplicação das fórmulas e conceitos contidos em Mueller-Dombois \& Ellenberg (1974).

A diversidade florística do conjunto de parcelas, como estimativa da diversidade alfa, foi determinada pelo cálculo do índice de Shannon na base $\left(\mathrm{H}^{\prime}\right)$ (Magurran 2004), fundamentado na abundância proporcional de espécies, que busca unir a riqueza de espécies e a similaridade em uma única informação (Felfili \& Rezende, 2003), porém atribui maior peso às espécies raras. Para Felfili \& Rezende (2003), os valores de $\mathrm{H}^{\prime}$ geralmente situamse entre 1,5 e 3,5 e, quanto maior seu valor, maior a diversidade de espécies. Para separar a equabilidade, ou seja, a variabilidade na abundância de espécies, calculou-se o índice de uniformidade de Pielou (J') (Felfili \& Rezende, 2003; Magurran 2004), que varia de 0 a 1 e, quanto maior seu valor, mais uniforme é a distribuição das espécies.

Realizou-se uma avaliação da estrutura diamétrica dos indivíduos, utilizando-se a fórmula de Spiegel para o estabelecimento dos intervalos de classe ideais (Felfili \& Rezende, 2003).

Avaliou-se a similaridade entre as parcelas de forma qualitativa pelo índice de Sørensen e de forma quantitativa pelo índice de Czekanowski, calculados utilizando-se o programa MVSP 3.1 - MultiVariate Statistical Package (Kovach, 1993). 

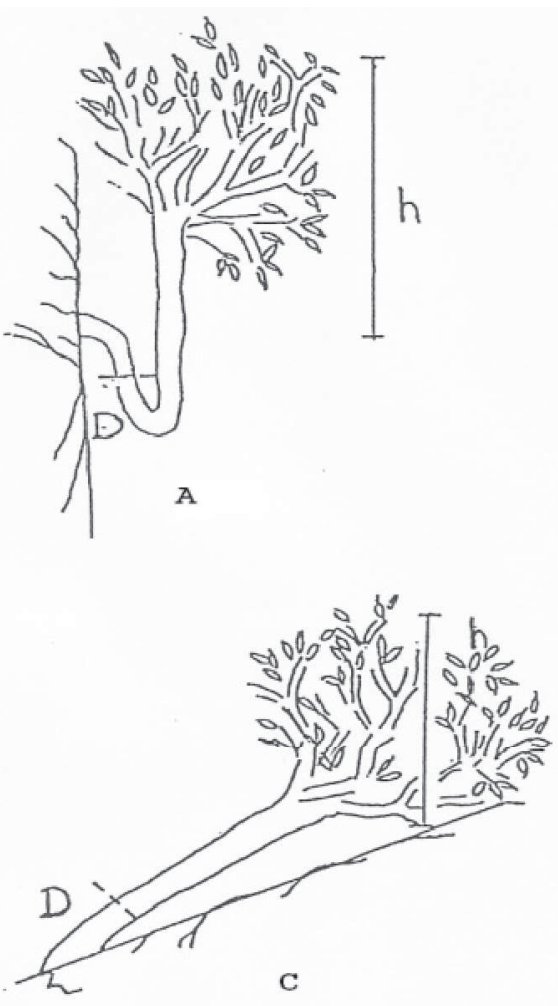
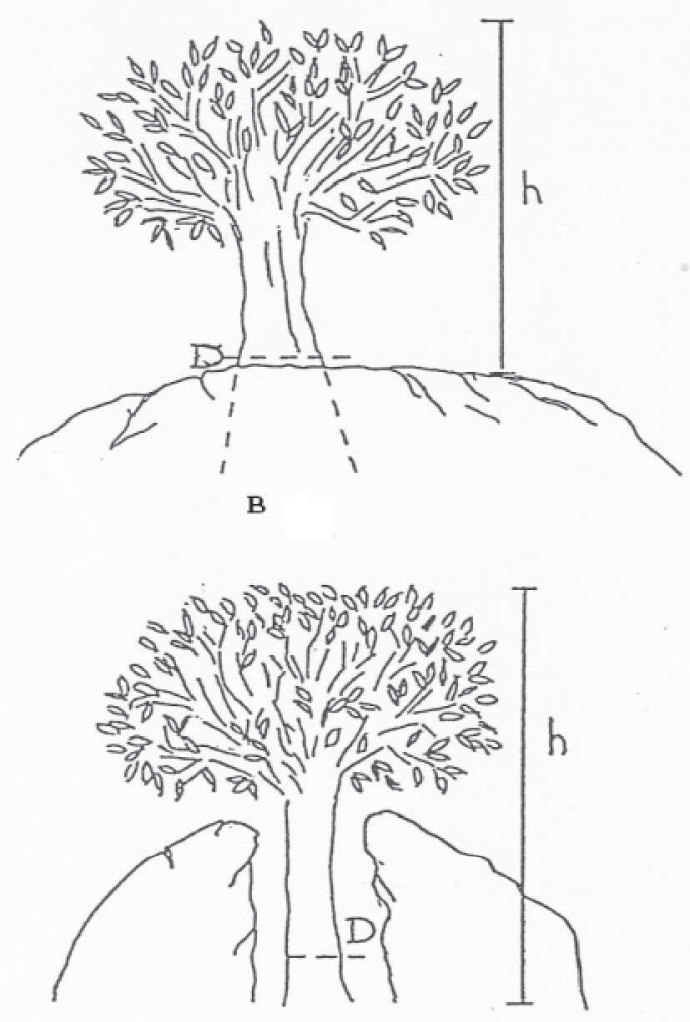

D

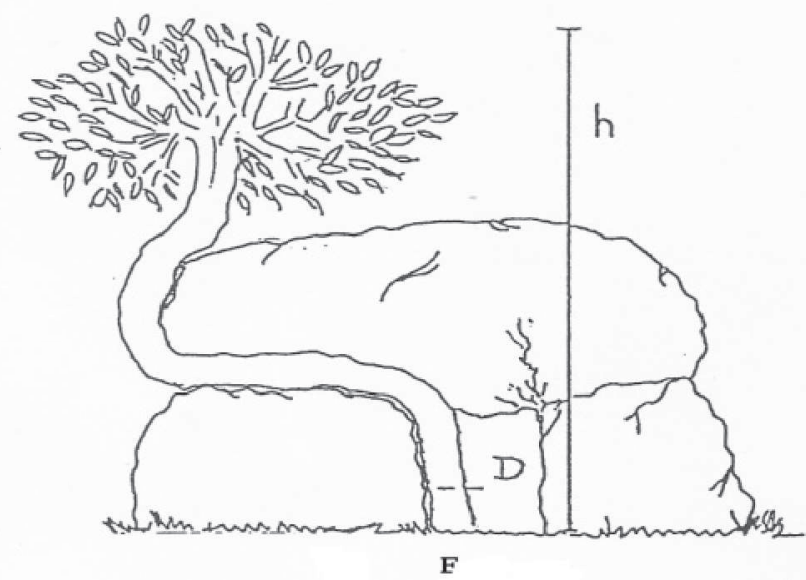

Figura 3 - Metodologia e alterações realizadas na medição de diâmetro (D) e altura (h) dos exemplares estudados em área de cerrado rupestre próxima aos Três Picos, no Parque Estadual dos Pireneus, Pirenópolis, Goiás (Moura 2006). A. Árvore enraizada em um paredão rochoso. Diâmetro medido a partir do ponto de inserção na rocha, seguindo o crescimento do indivíduo. Altura medida da copa ao ponto de inserção na rocha; B. Árvore com sua base no interior de uma rocha, sem acesso aos $30 \mathrm{~cm}$ da base do indivíduo. O diâmetro e a altura foram medidos no ponto visível em que a árvore surge da rocha; C. Árvore em terreno inclinado. Altura medida objetivando obter a projeção vertical da copa ao solo; D. Arvore entre rochas, mas com pontos de medição de diâmetro e altura acessíveis; E. Árvore em terreno plano, porém crescendo de forma inclinada. Altura medida objetivando obter a projeção vertical da copa ao solo; F. Árvore tortuosa entre rochas, com ponto de medição de diâmetros e alturas acessíveis. Muito comum em indivíduos da espécie Clusia burchellii. 


\section{Resultados e discussão}

A densidade de indivíduos lenhosos com diâmetro $\geq 5 \mathrm{~cm}$ foi de 507 indivíduos $/$ ha, com intervalo de confiança IC = $(507+70,83<\mathrm{M}<507-70,83)=95 \%$ e erro padrão de $7,88 \%$; a área basal foi de $3,91 \mathrm{~m}^{2} / \mathrm{ha}$, com IC $=(3,91+1<\mathrm{M}<3,91-1)=95 \%$ e erro padrão de $13,32 \%$. De acordo com o que Péllico Netto \& Brena (1997) preconizam, um erro padrão de $10 \%$ é suficiente para avaliar parâmetros quantitativos de florestas com o objetivo de planejamento da produção. McCune \& Grace (2002) ponderam que erros padrões de até $20 \%$ podem ser aceitos para avaliações da estrutura comunitária. Por analogia, podem-se considerar os valores médios encontrados no presente estudo, com suas respectivas margens de erro, suficientes para representar a densidade e a área basal da comunidade.

A diversidade de espécies, estimada pelo índice de Shannon $\left(\mathrm{H}^{\prime}\right)$, foi de 3,33 e a equabilidade $\left(\mathrm{J}^{\prime}\right), 0,82$, valores posicionados na faixa de variação daqueles estimados em outros trabalhos realizados utilizando a mesma metodologia em áreas de cerrado sensu stricto sobre diferentes tipos de solo (Tabela 1). Desse modo, a superfície rochosa não parece influenciar a diversidade de espécies ou mesmo a distribuição equitativa dos indivíduos, visto que os valores encontrados nesta pesquisa são similares aos de levantamentos realizados para Latossolos (Fonseca \& Silva Júnior, 2004; Nogueira et al., 2001) e Neossolos Quartzarênicos (Felfili et al., 2001a).

Na Tabela 1 constam os valores de densidade e área basal de alguns levantamentos realizados por vários autores em áreas de cerrado sensu stricto e cerrado rupestre empregando a mesma metodologia utilizada no presente estudo. Percebe-se que o valor de área basal $\left(\mathrm{m}^{2} / \mathrm{ha}\right)$ observado neste trabalho é muito próximo ao encontrado por Amaral et al. (2006) em uma área de cerrado rupestre em Brasília, Distrito Federal, porém mais baixo que o de outros estudos mostrados na Tabela 1; além disso, o número de indivíduos obtido nesta pesquisa está entre os mais baixos encontrados nos estudos comparados. Isso pode indicar que nesta área a vegetação é mais aberta, aproximando-se da descrição de cerrado rupestre feita por Ribeiro \& Walter (1998), ou a existência de distúrbios locais.

De modo geral, a curva espécie-área (Figura 4) desta pesquisa assemelha-se àquelas obtidas em estudos realizados em Cerrado, como no Distrito Federal (Felfili \& Silva Júnior, 1992; Assunção \& Felfili, 2004), em seis localidades da Chapada Pratinha, nos estado de Goiás e Minas Gerais e no Distrito Federal (Felfili \& Felfili, 2001) e em quatro localidades da Chapada do Espigão Mestre do São Francisco, nos estados de Minas Gerais e Bahia (Felfili \& Imaña-Encinas, 2001).

Percebe-se que o número de espécies amostradas foi muito maior nas primeiras três parcelas, aumentando apenas de forma moderada daí por diante. Na quinta parcela $(50 \%$ da amostra), 80,3\% do total de espécies já havia sido amostrado e na sétima parcela este valor subiu para $91 \%$. Apesar de uma nova espécie ainda ter sido acrescida na décima parcela, o tamanho da amostra foi abrangente com relação à composição florística e estrutural desta comunidade, pois a maioria das espécies foi amostrada na primeira metade do levantamento.

As 56 espécies encontradas estão distribuídas em 45 gêneros e 30 famílias (Tabela 2), das quais, seis famílias contribuíram com $51,78 \%$ do total de espécies. A família Myrtaceae apresentou o maior número de espécies (8), seguida por Melastomataceae e Fabaceae (6 cada), Malpighiaceae (4) e Clusiaceae (3). Fabaceae, que é citada por Mendonça et al. (1998) como a família de fanerógamas mais diversificada do bioma Cerrado, foi a que apresentou maior riqueza de espécies arbóreas em quase todas as áreas amostradas por Ribeiro et al. (1985), Felfili et al. (1993) Felfili et al. (1997), Rossi et al. (1998), Felfili et al. (2001a) e nas áreas estudadas por Assunção \& Felfili (2004) e Fonseca \& Silva Júnior (2004) no Distrito Federal, juntamente com as famílias Myrtaceae e Vochysiaceae. Em uma área de cerrado rupestre em Brasília, DF, amostrada por Amaral et al. (2006), as famílias Fabaceae (9), Melastomataceae e Malpighiaceae (4 cada) foram as mais ricas em espécies. Na presente pesquisa, do total, 21 famílias (70\%) apresentaram apenas uma espécie, representando $41,9 \%$ da dominância, $29,6 \%$ da densidade e $36,7 \%$ da freqüência. 


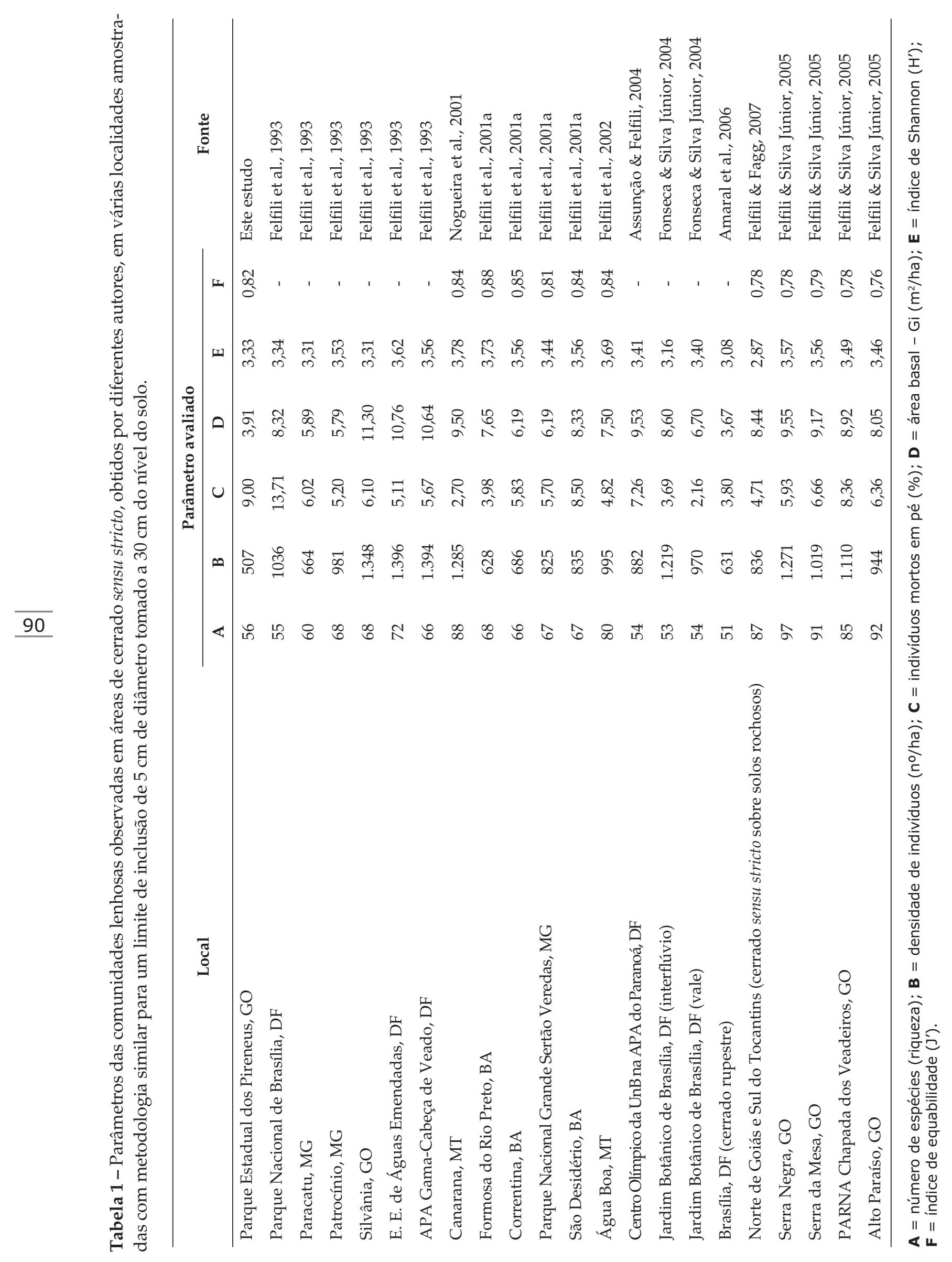




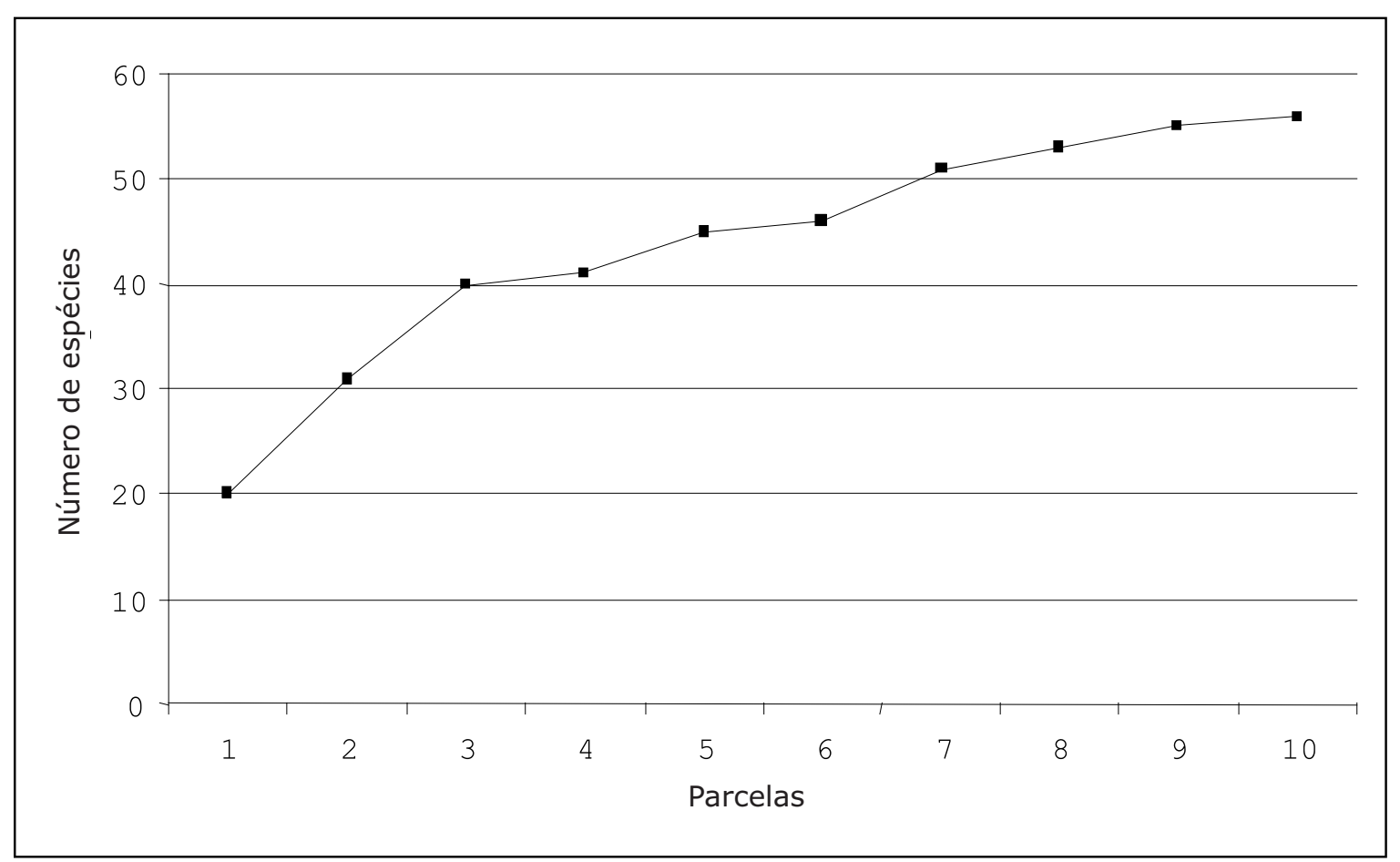

Figura 4 - Curva espécie-área da localidade estudada, em cerrado rupestre próxima aos Três Picos, no Parque Estadual dos Pireneus, Pirenópolis, Goiás.

A ocorrência de concentração de muitas espécies em poucas famílias e da presença de grande número de famílias com reduzido número de espécies também foi observada nas áreas em que os outros estudos acima mencionados foram realizados e é uma característica usual em levantamentos feitos em áreas de cerrado (Felfili et al., 2004).

Os gêneros que apresentaram os maiores números de espécies foram Miconia (4), Myrcia, Eugenia, Aspidosperma, Byrsonima, Psidium, Kielmeyera, Tibouchina e Guapira (2 cada). As dez espécies com maior VI (Tabela 2) foram: Psidium myrsinites, Sclerolobium paniculatum, Norantea adamantium, Byrsonima coccolobifolia, Ocotea pomaderroides, Clusia burchellii, Alchornea triplinervia, Myrsine guianensis, Miconia pohliana e Styrax ferrugineus, que totalizaram $52,3 \%$ do VI total, $62,4 \%$ da dominância total e $54,4 \%$ da densidade total, podendo ser consideradas as espécies que obtiveram maior sucesso na exploração dos recursos daquele ambiente.

A espécie Sclerolobium paniculatum também foi citada entre as dez primeiras em VI em áreas de cerrado sensu stricto na Estação Ecológica de Águas Emendadas e na APA GamaCabeça de Veado, ambas no Distrito Federal, assim como em Paracatu, Minas Gerais (Felfili et al., 1993); em áreas de cerrado sensu stricto no município de São Desidério, Bahia (Felfili et al., 2001a); em uma área de cerrado denso no Distrito Federal (Andrade et al., 2002); e em cerrado rupestre em Brasília, Distrito Federal (Amaral et al., 2006). Styrax ferrugineus também constou entre as dez espécies de maior VI na APA do Paranoá (Assunção \& Felfili, 2004) e no Jardim Botânico de Brasília (Fonseca \& Silva Júnior, 2004), ambos localizados no Distrito Federal. Byrsonima coccolobifolia também se destacou entre as dez espécies com maior VI em uma área estudada em Formosa do Rio Preto, Bahia, por Felfili et al. (2001a), na APA do Paranoá, no Distrito Federal (Assunção \& Felfili, 2004) e em áreas estudadas no norte de Goiás e no sul do Tocantins (Felfili \& Fagg, 2007).

Nenhuma espécie teve ocorrência em todas as dez parcelas, porém duas apareceram em nove parcelas, estando também entre as dez espécies de maior VI: Psidium myrsinites e Byrsonima coccolobifolia.

Entre todas as espécies, 25 apareceram em somente uma das parcelas, 19 foram representadas por apenas um indivíduo e 30 apresentaram VI menor que $10 \%$ do maior valor 


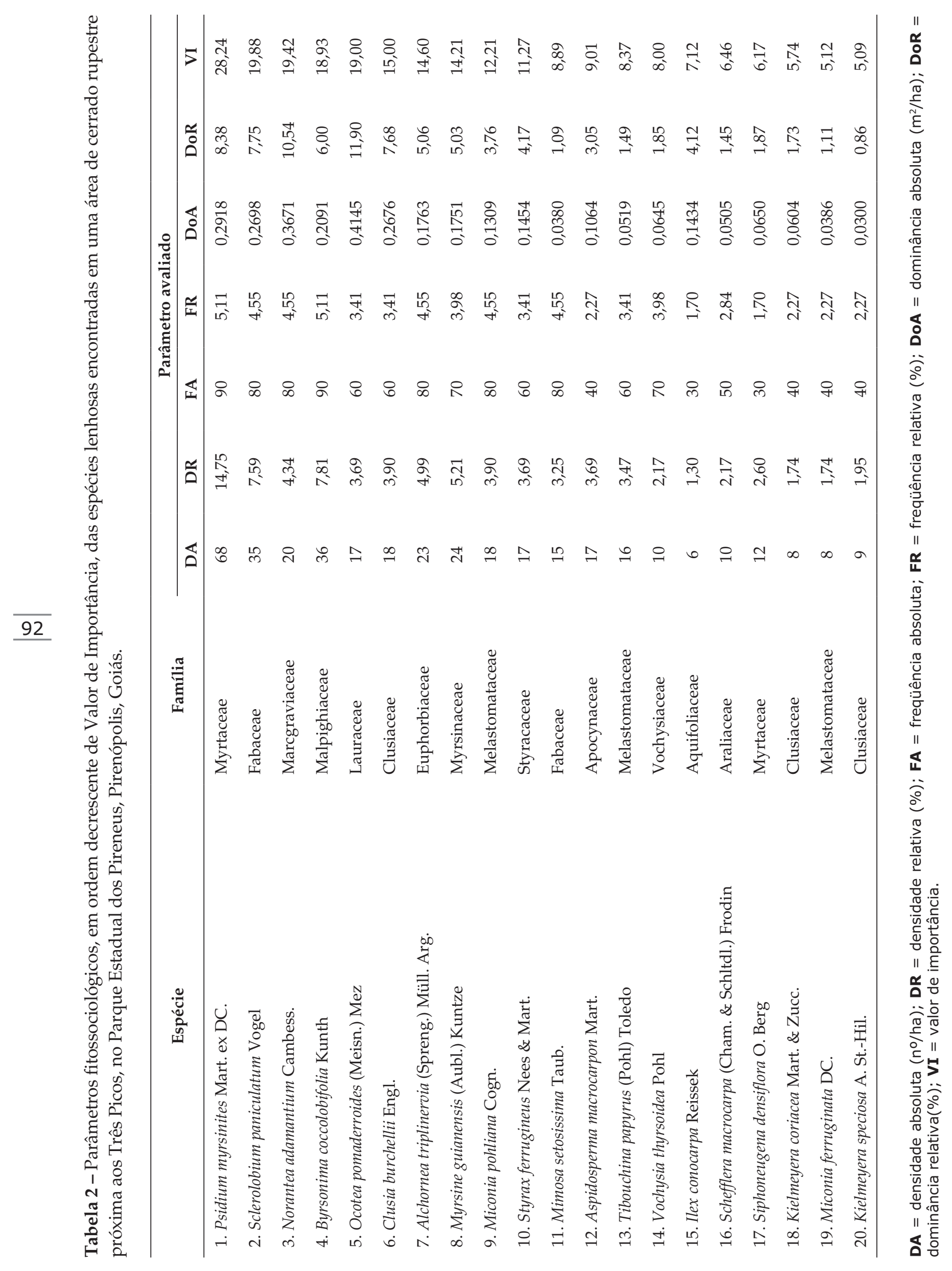




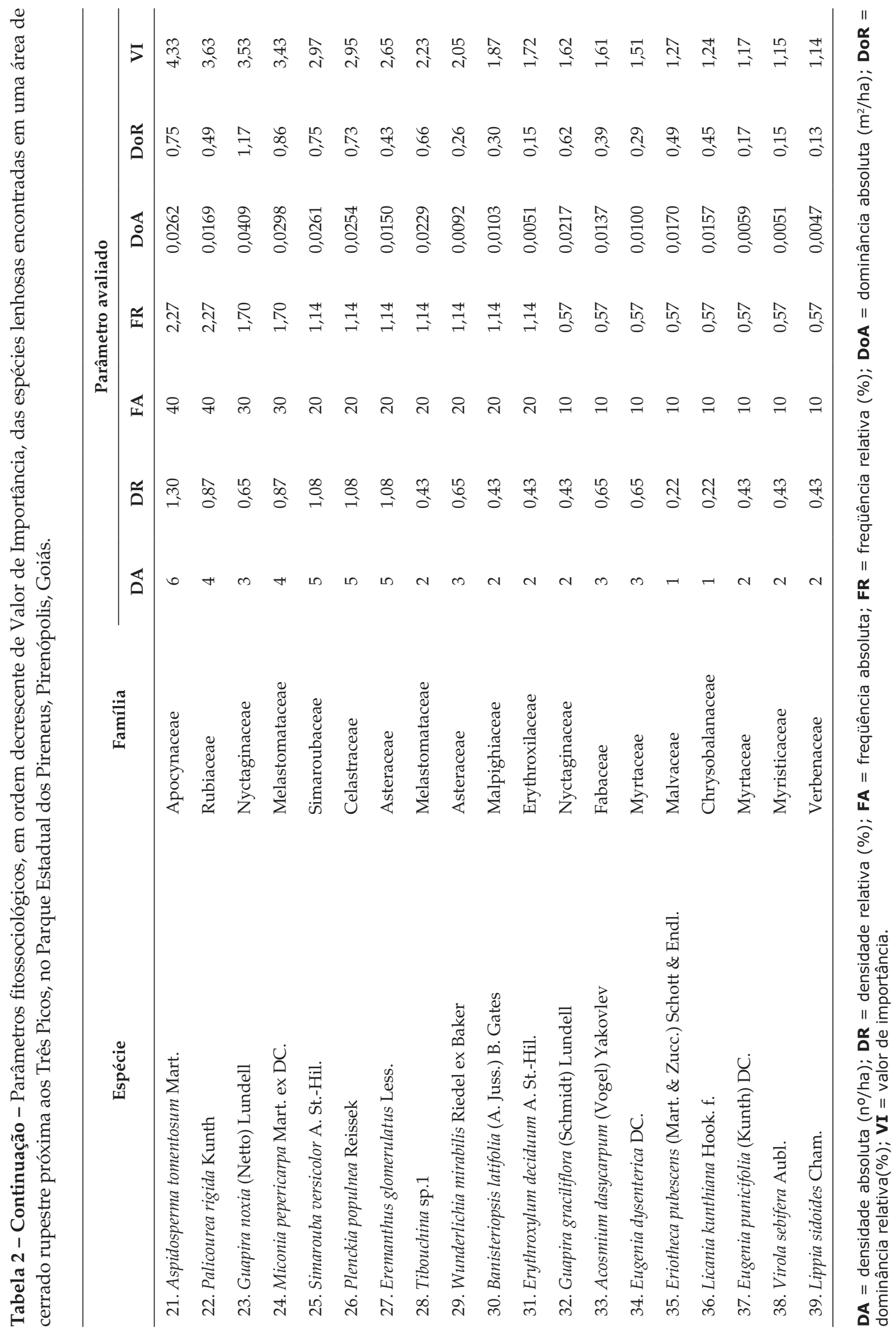




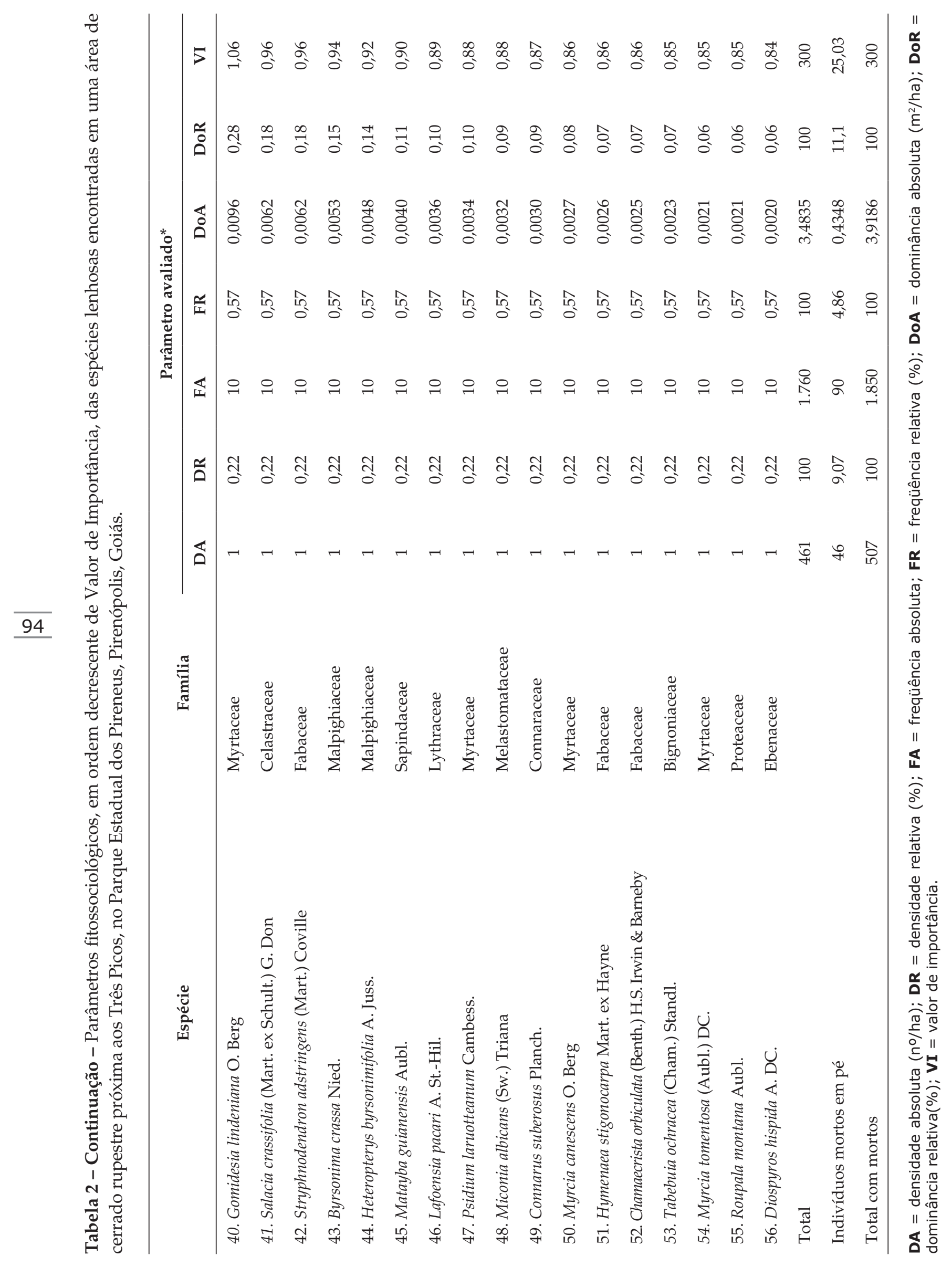


encontrado $(25,72)$, o que pode indicar que esta comunidade se caracteriza pela existência de poucas espécies dominantes.

Todas as espécies encontradas durante este trabalho constam na listagem de Mendonça et al. (1998), que compreende as espécies de fanerógamas registradas para o Cerrado. Já na listagem de 617 espécies lenhosas apresentada por Ratter et al. $(2000,2003)$, que analisam a composição florística e o número de ocorrências em 376 áreas de cerrado e de savana amazônica, não constam Clusia burchellii, Licania kunthiana, Tibouchina papyrus e Lippia sidoides. Do total de espécies avaliadas por Ratter et al. (2003), 11 podem ser consideradas de ampla distribuição no Cerrado, entre elas Byrsonima coccolobifolia, que está entre as dez espécies mais importantes em VI nesta pesquisa. Por outro lado, três dessas dez espécies exibiram distribuição bastante limitada no bioma Cerrado: Norantea adamantium, Miconia pohliana e Ocotea pomaderroides. Já Alchornea triplinervia é citada por Ratter et al. (2000) como uma espécie de distribuição restrita no bioma.

Em um estudo sobre a família Marcgraviaceae no estado de Goiás, Peixoto (1985) concluiu que Norantea adamantium é restrita aos campos rupestres, ocorrendo em altitude elevada. Essa mesma espécie consta na listagem de Mendonça et al. (1998) ocorrendo nas fitofisionomias de campo, cerrado e campo rupestre.

A espécie Clusia burchellii é citada por Mendonça et al. (1998) como ocorrente em mata seca e cerrado, e embora não seja muito mencionada na literatura, podendo ser considerada pouco comum ou rara no cerrado, vem sendo encontrada no município de Cavalcante, Goiás e em outras localidades de solos rasos e rochosos.

Tibouchina papyrus possui distribuição restrita aos estados de Goiás, com ocorrências na Serra dos Pireneus, na Serra Dourada, na Chapada dos Veadeiros (Munhoz \& Proença, 1998; Rizzo, 1970), e Tocantins, ocorrendo na Serra da Natividade (obs. pess.).

Com base nessas informações, verificase que o cerrado rupestre na área em estudo apresenta composição florística característica, composta por espécies provavelmente selecionadas pela pequena profundidade do solo e pelo substrato rochoso, como Norantea adamantium, Alchornea triplinervia e Clusia burchellii, assim como por espécies generalistas das fisionomias de cerrado.

De acordo com a lista da flora ameaçada de extinção no Brasil (Fundação Biodiversitas, 2008), Tibouchina papyrus encontra-se classificada na categoria vulnerável. No Paraná, as espécies Byrsonima coccolobifolia e Stryphnodendron adstringens foram classificadas como raras. Ocotea pomaderroides pertence à categoria em perigo de extinção no estado de Minas Gerais e Roupala montana é uma espécie vulnerável à extinção em São Paulo. Entretanto, vale ressaltar que B. coccolobifolia, S. adstringens e $R$. montana ocorrem, em geral, com distribuição ampla no Brasil Central. Por outro lado, O. pomaderroides, assim como as demais espécies da família Lauraceae, são pouco comuns em ambientes de cerrado e mais freqüentes em matas de galeria (Felfili et al., 2001b).

Os indivíduos mortos em pé representaram 9\% das árvores amostradas (Tabela 2) e ocorreram em nove parcelas, com a maior dominância relativa $(11,1 \%)$, a segunda maior densidade relativa $(9,07 \%)$, a segunda maior freqüência relativa $(4,86 \%)$ e o segundo maior VI $(8,3 \%$ do total). Esses valores são elevados, uma vez que a densidade relativa dos indivíduos mortos em 15 localidades do Brasil Central, incluindo as Chapadas dos Veadeiros, Pratinha e Espigão Mestre (Felfili et al., 2004), e também em área de cerrado rupestre amostrada por Amaral et al. (2006), variou entre 3\% a $10 \%$, situando-se em torno de $5 \%$ na maioria destas áreas. O elevado percentual de árvores mortas pode indicar a ocorrência de distúrbios recentes (Felfili \& Silva Júnior, 1992), a existência de uma dinâmica acelerada no ambiente rupestre ou ainda uma decomposição mais lenta decorrente da escassez de substrato.

A distribuição diamétrica dos indivíduos vivos amostrados apresentou formato de "J" invertido (Figura 5), com 254 indivíduos (54,9\% do total) apresentando diâmetros na classe entre $5 \mathrm{~cm}$ e $8 \mathrm{~cm}, 105$ (22,7\%) na classe entre $8 \mathrm{~cm}$ e $11 \mathrm{~cm}, 56(12,1 \%)$ na classe entre $11 \mathrm{~cm}$ e $14 \mathrm{~cm}$ e $47(10,1 \%)$ nas classes compreendidas entre $14 \mathrm{~cm}$ e $41 \mathrm{~cm}$.

Quando se analisa a curva de distribuição diamétrica em relação ao número de es- 


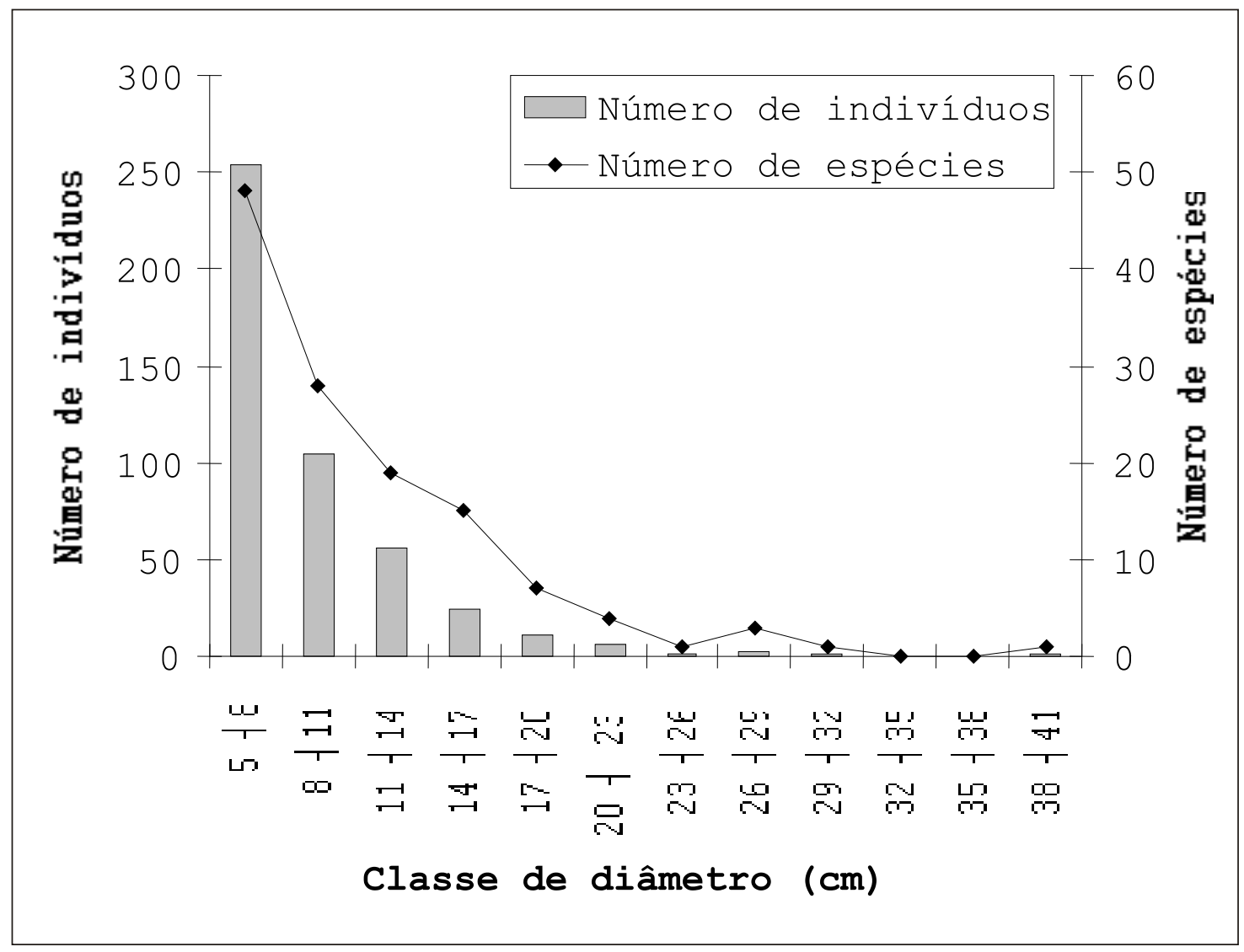

Figura 5 - Distribuição por classes de diâmetro dos indivíduos vivos e das espécies amostrados em área de cerrado rupestre próxima aos Três Picos, no Parque Estadual dos Pireneus, Pirenópolis, Goiás.

pécies encontradas (Figura 5), percebe-se a mesma tendência ao formato de "J" invertido, com $85,7 \%$ das espécies pertencentes à primeira classe, o que significa que há recrutamento de quase todas as espécies nesta classe. Aquelas espécies que ocorreram apenas na primeira classe são de pequeno porte e dominam o ambiente em número de indivíduos, uma vez que apenas uma espécie atingiu a maior classe, com até $41 \mathrm{~cm}$ de diâmetro. As espécies de grande porte, com diâmetro do tronco superior a $20 \mathrm{~cm}$, foram Alchornea triplinervia, Myrsine guianensis, Clusia burchellii, Ilex conocarpa, Norantea adamantium e Ocotea pomaderroides, as quais também estiveram presentes na primeira classe de diâmetro, o que indica que as espécies de grande porte estão recrutando. $\mathrm{O}$ formato das duas curvas indica tendência de compensação entre recrutamento e mortalidade, sugerindo que a comunidade tem capacidade de auto-regeneração.

Das 56 espécies estudadas, 32 apresentaram altura máxima inferior a $4 \mathrm{~m}, 17$ variaram entre $4 \mathrm{~m}$ e $5 \mathrm{~m}$ e apenas sete espécies atingiram altura superior a $5 \mathrm{~m}$. Sclerolobium paniculatum, Norantea adamantium, Styrax ferrugineus e Schefflera macrocarpa apresentaram variação considerável no porte dos indivíduos, porém não ultrapassaram $6 \mathrm{~m}$. Entre essas quatro espécies, apenas $N$. adamantium é nativa de ambientes rupestres (Peixoto, 1985), sendo as demais de ampla distribuição no bioma Cerrado (Felfili et al., 2004; Ratter et al., 2003), parecendo ocupar amplos nichos ecológicos com grande capacidade de adaptação às diversas condições deste ambiente.

$\mathrm{Na}$ Tabela 3 pode-se observar que as parcelas estudadas foram razoavelmente similares qualitativamente, ou seja, as espécies presentes não diferiram muito entre elas, visto que $37,7 \%$ das associações entre parcelas apresentaram valor igual ou maior que 0,5, citado por Felfili et al. (2004) como limite para considerar as parcelas como similares, isto é, com baixa diversidade beta. Por outro lado, quando se analisa a similaridade quantitati- 
Tabela 3 - Índices de similaridade de Sørensen (abaixo da diagonal) e de Czekanowski (acima da diagonal) entre as dez parcelas amostradas em área de cerrado rupestre próxima aos Três Picos no Parque Estadual dos Pireneus, Pirenópolis, Goiás. Os valores destacados em negrito são aqueles considerados elevados: superiores a 0,5 para o índice de Sørensen e 50 para o índice de Czekanowski.

\begin{tabular}{l|cccccccccc}
\hline & P1 & P2 & P3 & P4 & P5 & P6 & P7 & P8 & P9 & P10 \\
\cline { 2 - 11 } & & 32,56 & 17,78 & 25,32 & 27,59 & 28 & 20,51 & 25 & 26,32 & 26,51 \\
P2 & 0,37 & & 30,36 & 29,7 & 33,03 & 22,22 & 34 & 34,54 & 36,73 & 28,57 \\
P3 & 0,38 & 0,45 & & 20,95 & $\mathbf{5 4 , 8 7}$ & 31,58 & 34,61 & 57,89 & 31,37 & 44,04 \\
P4 & 0,41 & $\mathbf{0 , 5 6}$ & 0,39 & & 31,37 & 27,69 & 40,86 & 27,18 & 46,15 & $\mathbf{5 9 , 1 8}$ \\
P5 & 0,34 & 0,46 & $\mathbf{0 , 6}$ & 0,46 & & 24,66 & 49,5 & $\mathbf{6 1 , 2 6}$ & 36,36 & 43,39 \\
P6 & 0,4 & 0,43 & $\mathbf{0 , 5 6}$ & $\mathbf{0 , 5}$ & 0,39 & & 21,87 & 40,54 & 32,26 & 34,78 \\
P7 & 0,34 & 0,36 & 0,43 & 0,34 & 0,44 & 0,4 & & 43,14 & 37,78 & 45,36 \\
P8 & 0,39 & 0,46 & $\mathbf{0 , 6 5}$ & 0,4 & 0,67 & $\mathbf{0 , 5 2}$ & 0,44 & & 44 & 42,99 \\
P9 & $\mathbf{0 , 4 1}$ & $\mathbf{0 , 4 4}$ & $\mathbf{0 , 5}$ & $\mathbf{0 , 5 7}$ & 0,47 & $\mathbf{0 , 5 8}$ & 0,41 & $\mathbf{0 , 5 1}$ & & 46,32 \\
$\mathbf{P 1 0}$ & $\mathbf{0 , 4 4}$ & $\mathbf{0 , 5 6}$ & $\mathbf{0 , 6}$ & $\mathbf{0 , 5 7}$ & 0,57 & $\mathbf{0 , 5 8}$ & 0,44 & $\mathbf{0 , 5 7}$ & $\mathbf{0 , 6 3}$ & \\
\hline
\end{tabular}

vamente, somente $8,8 \%$ das associações entre parcelas apresentam valor considerado alto (superior a 50). Assim, as parcelas são muito mais parecidas entre si com relação à presença de espécies do que em relação à densidade delas, resultado que corrobora os apresentados por Felfili et al. (2004). Isso sugere que a densidade de indivíduos é um dos mais importantes fatores para a diferenciação de áreas de Cerrado e deve ser um parâmetro importante na seleção de áreas destinadas à conservação.

No trecho de cerrado sobre rochas do Parque Estadual dos Pireneus, a diversidade beta foi elevada quando se considerou a densidade de indivíduos, ou seja, houve grande variação no número de indivíduos entre parcelas, o que pode ter sido ocasionado pela variação da área coberta por rochas nas parcelas e pode constituir uma barreira para o crescimento e o desenvolvimento de plantas.

\section{Conclusão}

O cerrado sensu stricto que ocorre sobre os afloramentos rochosos na área em estudo apresenta flora peculiar, composta por espé- cies como Norantea adamantium, Clusia burchellii e Alchornea triplinervia, selecionadas pela pequena profundidade do solo e pela escassez de substrato nos litossolos e cambissolos dos afloramentos, assim como por espécies generalistas das fisionomias de cerrado. As famílias Myrtaceae, Melastomataceae, Fabaceae, Malpighiaceae e Clusiaceae foram predominantes e corresponderam a $48,2 \%$ das espécies presentes na área. Algumas espécies encontradas constam na lista da flora ameaçada de extinção no Brasil.

A estrutura observada encontra-se no limite inferior de densidade em comparação com outras amostragens de cerrado sensu stricto no bioma realizadas com a mesma metodologia (Felfili et al., 2004). Porém apresenta área basal por hectare bastante inferior, o que pode indicar a existência de distúrbios locais ou que no local estudado a vegetação é mais aberta, aproximando-se da descrição de cerrado rupestre de Ribeiro \& Walter (1998).

A diversidade alfa encontrada foi elevada, enquanto a diversidade beta, representada pelo inverso da similaridade entre parcelas, cresceu quando se considerou a densidade das espécies, sugerindo que o tamanho das 
populações é um importante diferenciador entre áreas de cerrados sobre afloramentos rochosos.

\section{Agradecimentos}

Agradecemos a todos os que auxiliaram nos trabalhos de campo: Rafael Machado, Alexandre Almeida, Gilberto e Fernando Morato, Damiana Ossami, Maria da Glória Gomes, Climbiê Hall, Éder Júnior, Tatiana L. Melo, Míriam P. Pinto, Thiago Rangel, Ismael M. Pereira e Cecillia A. Pereira, que desenhou a Figura 3. Nossos especiais agradecimentos à CAPES, pela concessão da bolsa de mestrado durante o segundo ano do desenvolvimento do trabalho; ao Dr. Piero Delprete, pela identificação das espécies de Rubiaceae; à Dra. Carolyn Elinore Barnes Proença, pela identificação das espécies de Myrtaceae; a Newton Rodrigues e Benedito Alísio da Silva Pereira, pelo auxílio na identificação de algumas espécies.

\section{ReferênCIAS}

Agência Ambiental de Goiás \& Nativa. 2002. Parque Estadual dos Pireneus. Relatório inicial: contextualização do parque. Goiânia.

Agência Ambiental de Goiás \& Nativa. 2003a. Consolidação dos subsídios da oficina de planejamento: elaboração de serviços de engenharia e de plano de manejo do Parque Estadual da Serra dos Pireneus. Goiânia.

Agência Ambiental de Goiás \& Nativa. 2003b. Parque Estadual da Serra dos Pireneus. Relatório parcial: consolidação das pesquisas de campo. Goiânia.

Alho, C. J. R. \& E. S. Martins. 1995. De grão em grão o cerrado perde espaço. WWF, Brasília, 66 pp.

Almeida Júnior, J. M. G. 1993. Uma proposta de ecologia humana para o cerrado, $\mathrm{p}$. 569-583. In: M. N. Pinto (Org), Cerrado: caracterização, ocupação e perspectivas. Brasília, Editora da Universidade de Brasília - Edunb, Secretaria do Meio Ambiente, Ciência e Tecnologia - SEMATEC.
Amaral, A. G., F. F. O. Pereira, \& C. B. R. Munhoz. 2006. Fitossociologia de uma área de cerrado rupestre na Fazenda Sucupira, Brasília-DF. Cerne 12: 350-359.

Andrade, L. A. Z., J. M. Felfili \& L. Violatti. 2002. Fitossociologia de uma área de cerrado denso na RECOR-IBGE, Brasília DF. Acta Bot. Bras. 16: 225-240.

Assunção, S. L. \& J. M. Felfili. 2004. Fitossociologia de um fragmento de cerrado sensu stricto na APA do Paranoá, DF, Brasil. Acta Bot. Bras. 18: 903-909.

Eiten, G. 1972. The Cerrado vegetation of Brazil. Bot. Rev. 38: 201-341.

Eiten, G. 1993. Vegetação do cerrado, p. 17-73. In: M. N. Pinto (Org), Cerrado: caracterização, ocupação e perspectivas. Brasília, Editora da Universidade de Brasília - Edunb, Secretaria do Meio Ambiente, Ciência e Tecnologia - SEMATEC.

Felfili, J. M. \& C. W. Fagg. 2007. Floristic composition, diversity and structure of the "cerrado" sensu stricto on rocky soils in northern Goiás and southern Tocantins, Brazil. Rev. Bras. Bot. 30: 375-385.

Felfili, J. M. \& J. Imaña-Encinas. 2001. Suficiência da amostragem no cerrado sensu stricto das quatro áreas estudadas na Chapada do Espigão Mestre São Francisco, p. 31-35. In: J. M. Felfili \& M. C. Silva Júnior (Orgs), Biogeografia do bioma cerrado: estudo fitofisionômico na Chapada do Espigão Mestre do São Francisco. Brasília, Universidade de Brasília.

Felfili, J. M. \& M. C. Silva Júnior. 1992. Floristic composition, phytosociology and comparison of cerrado and gallery forest at Fazenda Água Limpa, Federal District, Brazil, p. 393-416. In: P. A. Furley, J. Proctor \& J. A. Ratter (Eds), Nature and dynamics of forest-savanna boundaries. London,Chapman \& Hall.

Felfili, J. M. \& M. C. Silva Júnior. 2001. Biogeografia do bioma cerrado: estudo fitofisionômico na Chapada do Espigão Mestre do São Francisco. Universidade de Brasília, Departamento de Engenharia Florestal, Brasília, 152 pp.

Felfili, J. M. \& M. C. Silva Júnior. 2005. Diversidade alfa e beta no cerrado sensu stricto, Distrito Federal, Goiás, Minas Gerais e Bahia, p. 143-154. In: A. Scariot, J. C. Sou- 
sa-Silva \& J. M. Felfili (Orgs), Cerrado: ecologia, biodiversidade e conservação. Brasília, Ministério do Meio Ambiente.

Felfili, J. M., M. C. Silva Júnior, A. C. Sevilha, A. V. Rezende, P. E. Nogueira, B. M. T. Walter, F. C. Silva \& M. A. S. Salgado. 2001a. Fitossociologia da vegetação arbórea, p. 35-56. In: J. M. Felfili \& M. C. Silva Júnior (Orgs), Biogeografia do bioma cerrado: estudo fitofisionômico na Chapada do Espigão Mestre do São Francisco. Brasília, Universidade de Brasília, Departamento de Engenharia Florestal.

Felfili, J. M., M. C. Silva Júnior, A. C. Sevilha, C. W. Fagg, B. M. T. Walter, P. E. Nogueira \& A. V. Rezende. 2004. Diversity, floristic and structural patterns of cerrado vegetation in Central Brazil. Plant Ecol. 175: 37-46.

Felfili, J. M., M. C. Silva Júnior, A. V. Rezende, J. W. B. Machado, B. M. T. Walter, P. E. Nogueira \& J. D. Hay. 1993. Análise comparativa da florística e fitossociologia da vegetação arbórea do cerrado sensu stricto na Chapada Pratinha, DF - Brasil. Acta Bot. Bras. 6: 27-46.

Felfili, J. M., M. C. Silva Júnior, A. V. Rezende, P. E. Nogueira, B. M. T. Walter, M. C. Felfili, M. A. Silva \& J. Imaña-Encinas. 1997. Comparação florística e fitossociológica do cerrado nas Chapadas Pratinha e dos Veadeiros, p. 6-11. In: L. L. Leite \& C. H. Saito (Eds), Contribuição ao conhecimento ecológico do Cerrado. Brasília, Editora da Universidade de Brasília.

Felfili, J. M., P. E. Nogueira, M. C. Silva Júnior, B. S. Marimon \& W. B. C. Delitti. 2002. Composição florística e fitossociologia do cerrado sentido restrito no município de Água Boa - MT. Acta Bot. Bras. 16: 103-112.

Felfili, J. M., R. C. Mendonça, B. M. T. Walter, M. C. Silva Júnior, M. G. Nóbrega, C. W. Fagg, A. C. Sevilha \& M. A. Silva. 2001b. Flora fanerogâmica das matas de galeria e ciliares do Brasil Central, p. 195263. In: J. F. Ribeiro, C. E. L. Fonseca \& J. C. Sousa-Silva (Orgs), Cerrado: caracterização e recuperação de matas de galeria. Planaltina, Embrapa.
Felfili, M. C. \& J. M. Felfili. 2001. Diversidade alfa e beta no cerrado sensu stricto da Chapada Pratinha, Brasil. Acta Bot. Bras. 15: 243-254.

Felfili, J. M. \& R. P. Rezende. 2003. Conceitos e métodos em fitossociologia. Universidade de Brasília, Departamento de Engenharia Florestal, Brasília, 68 pp.

Fonseca, M. S. \& M. C. Silva Júnior. 2004. Fitossociologia e similaridade florística entre trechos de Cerrado sentido restrito em interflúvio e em vale no Jardim Botânico de Brasília, DF. Acta Bot. Bras. 18: 19-29.

Fundação Biodiversitas. 2008. Revisão da lista da flora brasileira ameaçada de extinção. Disponível em: <http://www.biodiversitas.org.br/florabr/consulta_fim.asp $>$. Acesso em: 20 jun. 2008.

Furley, P. A. 1999. The nature and diversity of neotropical savanna vegetation with particular reference to the Brazilian cerrados. Global Ecol. Biogeogr. 8: 223-241.

Kent, M. \& P. Coker. 1992. Vegetation description and analysis. Belhaven Press, London, $363 \mathrm{pp}$.

Klink, C. A. \& R. B. Machado. 2005. Conservation of the Brazilian cerrado. Cons. Biol. 19: 707-713.

Kovach, W. L. 1993. MVSP - Multivariate Statistical Package, version 3.1. Kovach Computing Services, Pentraeth.

Magurran, A. E. 2004. Measuring biological diversity. Blackwell Publishing, Oxford, 256 pp.

McCune, B. \& J. B. Grace. 2002. Analysis of ecological communities. MjM Software Design, Gleneden Beach, 300 pp.

Mendonça, R. C., J. M. Felfili, B. M. T. Walter, M. C. Silva Júnior, A. V. Rezende, T. S. Filgueiras \& P. E. Nogueira. 1998. Flora vascular do cerrado, p. 289-556. In: S. M. Sano \& S. P. Almeida (Eds), Cerrado: ambiente e flora. Planaltina, Embrapa.

Miranda, I. S., M. L. Absy \& G. H. Rebêlo. 2003. Community structure of woody plants of Roraima savannahs, Brazil. Pl. Ecol. 164: 109-123.

Moura, I. O. 2006. Fitossociologia de cerrado sensu stricto sobre afloramentos rochosos no Parque Estadual dos Pireneus, Pirenópolis, Goiás. Dissertação de mestrado, Universidade Federal de Goiás, Goiânia. 
Mueller-Dombois, D. \& H. Ellenberg. 1974. Aims and methods of vegetation ecology. John Wiley \& Sons, New York, 547 pp.

Munhoz, C. B. R. \& C. E. B. Proença. 1998. Composição florística do município de Alto Paraíso de Goiás na Chapada dos Veadeiros. Bol. Herb. E. P. Heringer 3: 102-150.

Myers, N., R. A. Mittermeier, C. G. Mittermeier, G. A. B. Fonseca \& J. Kent. 2000. Biodiversity hotspots for conservation priorities. Nature 403: 853-858.

Nogueira, P. E., J. M. Felfili, M. C. Silva Júnior, W. Delitti \& A. C. Sevilha. 2001. Composição florística e fitossociologia de um cerrado sentido restrito no município de Canarana, MT. Bol. Herb. E. P. Heringer 8: 28-43.

Oliveira-Filho, A. T. \& J. A. Ratter. 2002. Vegetation physionomies and wood flora of the Cerrado Biome, p. 91-120. In: P. S. Oliveira \& R. J. Marquis (Eds), The Cerrados of Brazil: ecology and natural history of a neotropical savanna. New York, Columbia University Press.

Peixoto, A. B. F. 1985. Marcgraviaceae, p. 1-32. In: J. Rizzo (Ed), Flora do estado de Goiás. Goiânia, Editora da Universidade Federal de Goiás. (Coleção Rizzo).

Péllico Netto, S. \& D. A. Brena. 1997. Inventário florestal. Editorado pelos autores, Curitiba, 316 pp.

Ratter, J. A., S. Bridgewater \& J. F. Ribeiro. 2003. Analysis of the floristic composition of the Brazilian cerrado vegetation III: comparison of the wood vegetation of 376 areas. Edinb. J. Bot. 60: 57-109.
Ratter, J. A., S. Bridgewater, J. R. Ribeiro, T. A. B. Dias \& M. R. Silva. 2000. Estudo preliminar da distribuição das espécies lenhosas da fitofisionomia cerrado sentido restrito nos estados compreendidos pelo bioma cerrado. Bol. Herb. E. P. Heringer 5: 5-43.

Reatto, A., J. R. Correia \& S. T. Spera. 1998. Solos do bioma cerrado: aspectos pedológicos, p. 47-86. In: S. M. Sano \& S. P. Almeida (Eds), Cerrado: ambiente e flora. Planaltina, Embrapa.

Ribeiro, J. F. \& B. M. T. Walter. 1998. Fitofisionomias do bioma cerrado, p. 89-166. In: S. M. Sano \& S. P. Almeida (Eds), Cerrado: ambiente e flora. Planaltina, Embrapa.

Ribeiro, J. F., J. C. S. Silva \& G. J. Batmanian. 1985. Fitossociologia de tipos fitofisionômicos de Cerrado em Planaltina - DF. Rev. Bras. Bot. 8: 131-142.

Rizzo, J. A. 1970. Contribuição ao conhecimento da Flora de Goiás - Área na Serra Dourada. Tese de livre-docência. Universidade Federal de Goiás, Goiânia.

Rizzo, J. A. 1996. Goiás: de Saint Hilaire e de hoje. Editora da Universidade Federal de Goiás, Goiânia, 81 pp. (Coleção Rizzo. Volume especial).

Rossi, C. V., M. C. Silva Júnior \& C. E. N. Santos. 1998. Fitossociologia do estrato arbóreo do cerrado sentido restrito no Parque Ecológico Norte, Brasília - DF. Bol. Herb. E. P. Heringer 2: 49-56.

The Angiosperm Phylogeny Group. 2003. An update of the Angiosperm Phylogeny Group classification for the orders and families of flowering plants: APG II. Bot. J. Linn. Soc. 144: 399-436.

Recebido em 09.III.2007 Aceito em 24.VI.2008 